УДК 37.06

\title{
ОСОБЕННОСТИ ИННОВАЦИОННОГО РАЗВИТИЯ ПРОФЕССИОНАЛЬНОГО ОБРАЗОВАНИЯ
}

\author{
Волков Сергей Вячеславович \\ кандидат психологических наук, доцент \\ ФГБОУ ВО РАНХиГС, КМПО, г. Москва
}

\begin{abstract}
Аннотация: В данной статье представлены некоторые особенности внедрения цифровых технологий в образовательном учреждении, ключевые задачи, которые должны решаться каждой образовательной организацией в рамках создания современной и безопасной цифровой образовательной среды. Приводиться реальный опыт решения различного рода задач в рамках применения дистанционных образовательных технологий структурного подразделения ФГБОУ ВО «Российская академия народного хозяйства и государственной службы при Президенте Российской Федерации» - Колледжа многоуровневого профессионального образования в режиме дистанционного обучения в период вынужденной изоляции в связи с пандемией, вызванной распространением новой коронавирусной инфекции «SARS-CoV-2».
\end{abstract}

Ключевые слова: Система дистанционного образования, цифровая образовательная среда, электронно-образовательный ресурс.

\section{FEATURES OF INNOVATIVE DEVELOPMENT OF PROFESSIONAL EDUCATION}

\section{Volkov Sergey Vyacheslavovich}

\begin{abstract}
This article presents some features of the introduction of digital technologies in an educational institution, the key tasks that should be solved by each educational organization in the framework of creating a modern and safe digital educational environment. The real experience of solving various tasks within the framework of the application of distance education technologies of the structural division of the Russian Presidential Academy of National Economy and Public Administration - a College of multi-level professional education in the distance
\end{abstract}


learning mode during the period of forced isolation due to the pandemic caused by the spread of the new coronavirus infection "SARS-CoV-2" is presented.

Key words: Distance education system, digital educational environment, electronic educational resource.

В современных реалиях жизни одним из ведущих трендов в образовании является внедрение цифровых технологий, которое неизбежно ведет к кардинальному изменению рынка труда, появлению новых компетенций, улучшению кооперации, повышению ответственности граждан, их способности принимать самостоятельные решения. Это, в свою очередь, служит поводом для последующей реорганизации всей существующей системы учебновоспитательного процесса.

Развитие цифровой экономики в России предполагает активную позицию образовательного сообщества по проектированию новых подходов к реализации образовательного процесса в условиях цифровизации профессионального образования. Цифровые технологии, социальные сети и различные мессенджеры внесли значимые изменения в общественные ценности, привели к сетевой идентификации личности человека. Появился новый тип обучающихся, которые самостоятельно определяют свою образовательную траекторию. Они мотивированы на личное саморазвитие и самоопределение, готовы и могут сочетать учебу с профессиональной деятельностью. Чтобы успешно решать задачи цифровизации, образованию необходимо пройти через определенную цифровую трансформацию. Цифровая трансформация образования, по мнению ученых, - это ответы на глобальные информационные вызовы, происходящие в мире [5].

Существующие сегодня системы образования в подавляющем большинстве стран мира сформированы еще в предыдущих технологических укладах, и по этой причине структурно, функционально и идеологически соответствовали требованиям того времени. Еще в 1998 г. Д. Ханна обращал внимание на новые вызовы, которые создает для образования цифровизация. Позднее М. Олсен и М. Петерс подробно рассмотрели механизм ее влияния на формы и методы обучения. Г. Ю. Беляев провел анализ негативных тенденций, созданных цифровизацией для системы образования. В.Г. Иванов, А.А. Кайбияйнен и Л. Т. Мифтахутдинова в свою очередь определили основные пути необходимых изменений. Одной из наиболее значимых новаций является активное внедрение в процесс обучения онлайн-технологий. История онлайн- 
образования значительно короче истории информационных технологий вообще. Можно сказать, что оно сегодня является своего рода пиком ИТразвития, появление которого было обусловлено не только технологической, но и общественной трансформацией, готовностью общества отойти от традиционных образовательных моделей - сегодня классические образовательные форматы становятся все менее и менее востребованными, в то время как число людей, использующих различные онлайн-ресурсы неуклонно растет [3;5].

В своих исследованиях А.Ю. Уваров отмечает, что цифровая трансформация образования должна сопровождаться «синергичным» обновлением содержания, которое приведет к кардинальному улучшению качества образования. По мнению А.Ю. Уварова, цифровая трансформация образования приведет общество к цифровой экономике если система образования будет соответствовать требованиям и возможностям цифрового общества. В цифровом пространстве традиционные педагогические теории попадают в совершенно новые условия. Формируется новая, цифровая педагогика, «кардинально изменяется функция педагога: от ретранслятора учебной информации до организатора процесса обучения» [6]. Очевидно, что нужно проектировать, экспериментировать и создавать новые работающие модели организации образовательного процесса, новые механизмы оценивания знаний, умений и компетенций, углубления связей между всеми уровнями обучения, налаживания контакта между образовательными институтами, студентами и работодателями, выстраивания эффективной системы непрерывного образования, обеспечивающие реальный переход от образования на всю жизнь к образованию через всю жизнь [3].

Современный этап цифровизации в образовании заключается в погружении всех его субъектов в цифровую образовательную среду. В цифровой среде единицей обучения становится активность студента, которая, в первую очередь, направлена на конкретные продуктивные действия с предложенной педагогом информацией или в процессе ее поиска, отбора и интерпретации. Например, активностью может быть просмотр видеоматериалов или прослушивание аудиоматериалов, работа со встроенной моделью, отработка умений на виртуальном тренажере, выполнение интерактивных заданий или самоконтроль. Реализовать активность - значит дослушать, прочитать или досмотреть до конца и выполнить задание, отработать с тренажером, моделью, найти правильные ответы в тесте и т. д. Цифровая 
образовательная среда предполагает иную архитектуру образовательного процесса. Образовательное содержание может доставляться через множество устройств и платформ, связанных друг с другом. Например, студент может получить задание в системе дистанционного обучения колледжа, обсудить его с педагогом и со своими одногруппниками в группе какой-либо социальной сети, задать вопросы преподавателю посредством мессенджера или по электронной почте, подготовиться к экзамену в электронном приложении или академии одной из ведущих компаний (как пример - взаимодействие колледжа с академией Cisco при подготовке системных администраторов, специалистов по компьютерным сетям), получить онлайн-сертификат соответствующего уровня и разместить его в электронном портфолио студента. В итоге наличие диплома CПО и сертификата академии Cisco дает выпускнику колледжа определенные конкурентные преимущества на рынке труда. На сегодняшний день все большее число ВУЗов предлагают абитуриенту оформить свое поступление на обучение по выбранной специальности посредством электронного приложения, без необходимости посещения приемной комиссии. Таким образом, цифровая образовательная среда обеспечивает выстраивание индивидуальной образовательной траектории, позволяет каждому студенту выбирать собственную образовательную траекторию, состоящую из активностей, которые нужны ему здесь и сейчас [2]. В связи с этим среда должна непрерывно анализировать потребности и способности студента и предлагать сценарии дальнейшего развития. Активности автономны, а вместе формируют бесконечное количество цепочек: курсов, квестов, кампаний - образовательных траекторий и тому подобное.

Среди ключевых задач, которые должны решаться каждой образовательной организацией в рамках создания современной и безопасной цифровой образовательной среды, следует отметить: внедрение целевой модели цифровой образовательной среды, обновление информационного наполнения и функциональных возможностей информационных ресурсов, в том числе открытых и общедоступных, повышение квалификации педагогических работников с целью повышения их компетенций в области современных технологий онлайн-обучения, обеспечение внедрения современных цифровых технологий в основные образовательные программы и программы дополнительного образования. Существует ряд определений понятия «цифровая образовательная среда». Большинство авторов сходятся во мнении, что цифровая образовательная среда (ЦОС) - это открытая совокупность 
информационных систем, предназначенных для обеспечения различных задач образовательного процесса. Среда принципиально отличается от системы тем, что она включает в себя совершенно разные элементы: как согласованные между собой, так и дублирующие, конкурирующие и даже антагонистичные. Это позволяет среде более динамично развиваться [1;2]. Так, Приказом Министерства просвещения РФ от 2 декабря 2019 г. № 649 утверждена Целевая модель цифровой образовательной среды, которая касается общеобразовательных и профессиональных образовательных организаций и регулирует отношения, связанные с созданием и развитием условий для реализации образовательных программ с применением электронного обучения, дистанционных образовательных технологий в условиях функционирования электронной информационно-образовательной среды. В соответствии с данным документом, цифровая образовательная среда включает в себя электронные информационные и образовательные ресурсы, совокупность информационных и телекоммуникационных технологий, соответствующих технических средств, обеспечивающих освоение образовательных программ обучающимися независимо от места их нахождения [4].

Целью нашей работы было изучение некоторых особенностей инновационного развития профессионального образования на примере структурного подразделения ФГБОУ ВО «Российская академия народного хозяйства и государственной службы при Президенте Российской Федерации» (далее - Академия) - Колледжа многоуровневого профессионального образования (далее - КМПО).

Для профессиональной образовательной организации цифровизация неразрывно связана с широким использованием в практике подготовки специалистов среднего звена дистанционных образовательных технологий. Под дистанционными образовательными технологиями мы понимаем образовательные технологии, реализуемые в основном с применением информационно-телекоммуникационных сетей при опосредованном (на расстоянии) взаимодействии обучающихся и педагогических работников. Для применения дистанционных образовательных технологий колледж обеспечивает условия для функционирования цифровой образовательной среды, включающей в себя: электронные информационные ресурсы, электронные образовательные ресурсы, совокупность информационных технологий, телекоммуникационных технологий, соответствующих технологических средств. При реализации образовательных программ с 
применением дистанционных образовательных технологий местом осуществления образовательной деятельности является местонахождение КМПО независимо от местонахождения обучающихся. Актуальность цифровизации, применения дистанционных образовательных технологий резко усилилась после вынужденного перехода к повсеместной дистанционной форме как мере защиты от пандемии «коронавируса».

В частности КМПО, как структурное подразделение Академии, на основании приказа РАНХиГС от 16.03.2020 г. «О мерах по переходу на обучение с применением дистанционных образовательных технологий» организованно перевел образовательный процесс в дистанционный формат.

Колледжем было развернуто исключительно онлайн-обучение в цифровой образовательной среде. Благодаря заблаговременной и системной работе по формированию и развитию цифровой образовательной среды в Академии, данная ситуация для основной части участников образовательного процесса не стала непреодолимым испытанием. Онлайн-обучение в колледже, организованное в системе дистанционного обучения (далее - СДО), предусматривало сочетание синхронного и асинхронного обучения. Синхронное онлайн-занятие обеспечивает электронное взаимодействие студента и преподавателя в конкретное время. Такие онлайн-лекции, вебинары, в первые дни проведения СДО, в период режима самоизоляции в стране, преподаватели колледжа проводили посредством видеосвязи с использованием онлайн-сервисов: Zoom, Skype . Но, как показала практика использования данных ресурсов, в их работе были выявлены ряд существенных недостатков: низкая защищенность видеоконференций от постороннего вмешательства, ограниченное количество участников конференции, ограничение сеанса по времени.

Учитывая выше перечисленные моменты, с апреля 2020 г. преподавателям колледжа было рекомендовано перейти на использование платформы MS Teams. K этому времени в Академии была налажена работа электронной образовательной платформы СДО и все преподаватели колледжа успешно прошли обучение по курсу повышения квалификации « Использование СДО в образовательном процессе с применением электронного обучения и дистанционных образовательных технологий (ЭО и ДОТ)» на базе СДО Moodle.

Асинхронные курсы отличаются тем, что преподаватель размещает в СДО на единой цифровой платформе дистанционного обучения Академии 
(https://lms.ranepa.ru/my/) в интернет электронные образовательные ресурсы электронные курсы, практикумы, ФОСы, а студенты работают с ними в любое удобное для них время. На платформе предусмотрена и обратная связь. Инициировать общение на форуме путем создания новой темы для обсуждения может как преподаватель, так и обучающийся. Срок ответа преподавателя регламентирован и не должен превышать 1 (одного) рабочего дня с момента публикации вопроса.

Сегодня педагогические работники успешно сочетают формат смешанного обучения, которое заключается в совмещении реального обучения лицом к лицу с преподавателем в аудитории и интерактивных возможностей электронных образовательных ресурсов (онлайн-лекции с самостоятельно организованной работой студентов с цифровым образовательным контентом, предусматривающей в том числе и обязательную обратную связь). На протяжении последнего года педагогический коллектив решал задачу разработки и эффективного использования цифрового образовательного контента, который должен соответствовать федеральным государственным образовательным стандартам, нормативным требованиям для применения в образовательном и воспитательном процессе. При разработке цифрового образовательного контента преподаватели должны четко представлять себе технологию и методики его использования и впоследствии эффективно применять данные технологии и методики при организации обучения с использованием дистанционных образовательных технологий и электронного обучения. Таким образом, на первый план была поставлена проблема обеспечения готовности педагогических работников колледжа активно участвовать в создании и развитии цифровой образовательной среды. В рамках решения данной проблемы было определено два аспекта: организационнометодический (повышение квалификации педагогов) и мотивационный. Традиционно в колледже сложилась модель непрерывного повышения квалификации, включающая в себя формальное и неформальное повышение квалификации. Формальное повышение квалификации заключается в организации обучения педагогических работников колледжа по дополнительным профессиональным программам, направленного на освоение технологий проектирования и использования цифровых образовательных ресурсов.

На начальном этапе перехода на СДО в Академии централизовано было организовано повышение квалификации педагогических работников, в том 
числе и работников КМПО, по программе « Использование СДО в образовательном процессе с применением электронного обучения и дистанционных образовательных технологий (ЭО и ДОТ)» на базе СДО Moodle. Охват обученных по программе составил 77 человек (93,9\% педагогических работников КМПО). Некоторые преподаватели в силу ряда причин (наличие ограничений по здоровью, возраст), оказались не готовы к освоению новых компетенций и решили закончить свою педагогическую деятельность. Повышение квалификации позволило преподавателям в кратчайшие сроки адаптироваться к новой форме осуществления образовательного процесса.

Однако результативность в части эффективной разработки педагогическими работниками колледжа электронных образовательных ресурсов, не превысила 19 \%. С учетом выявленной проблемы было принято решение продолжить работу по дальнейшему повышению квалификации педагогических работников по дополнительным профессиональным программам повышения квалификации «Разработка электронных образовательных ресурсов с использованием онлайн-конструкторов сайтов» и «Разработка электронных образовательных ресурсов с использованием возможностей СДО Moodle».

Организационно-методическое сопровождение программ повышения квалификации осуществляет методический совет колледжа, лекторами являются опытные преподаватели, добившиеся высоких результатов в разработке и использовании электронных образовательных ресурсов (ЭОР). Итогом реализации корпоративных программ повышения квалификации в ближайшей перспективе мы видим увеличение числа электронных образовательных ресурсов, среди которых будут иметь место целые сайты специальностей, предполагающие совместную разработку и использование цифрового образовательного контента, и электронные обучающие курсы по дисциплинам, междисциплинарным курсам, учебным практикам.

Опираясь на мнение ученых [6] и собственный опыт, не менее эффективным считаем неформальное повышение квалификации педагогов, которое будет реализовано в форме внутриколледжных методических конкурсов, организации участия в городских, областных и межрегиональных конкурсах, работе в составе рабочих групп, методических объединений, межрегиональных методических объединений, в подготовке к участию в городских, областных, всероссийских, международных семинарах, 
конференциях, в подготовке публикаций по проблемам разработки и использования цифрового образовательного контента.

В ближайшее время в колледже планируется организация и проведение на постоянной основе конкурса на лучший электронный образовательный peсурс. Номинации конкурса будут постоянно изменяться, что позволит увеличить число участников и качество представленных на конкурс электронных образовательных ресурсов. Лучшие ЭОР будут направляться для участия в областных и межрегиональных конкурсах. Преподавателиразработчики будут проводить мастер-классы по технологии использования разработанных ими электронных образовательных ресурсов в образовательном процессе как для педагогических работников колледжа в рамках заседаний ПЦК, методического совета, так и в рамках городских семинаров, конференций, заседаний.

Цифровой образовательный контент колледжа планируется разместить как на единой платформе дистанционного обучения Академии (СДО), так и на сайте КМПО.

На сегодняшний день, все участники образовательного процесса в колледже являются авторизованными пользователями СДО, имеют свои четко обозначенные права доступа и внутрисистемные роли: ассистент, преподаватель, автор курса, студент. Для организации работы преподавателей и студентов на сайте Академии размещен вводный курс «Организация работы на платформе», в котором представлены инструкции по работе с курсами, по использованию онлайн-сервисов по видеосвязи, собраны нормативные и методические материалы, представлены контакты специалистов технической поддержки. Преподаватели и студенты колледжа имеют доступ к платформе СДО посредством личного кабинета (Lk/ranepa.ru) при входе на который они используют персональную учетную запись домена ranepa.ru. Колледж самостоятельно определяет набор электронных ресурсов и приложений, которые допускаются к использованию в образовательном процессе, а также корректирует расписание занятий с учетом ресурсов, необходимых для реализации программ с применением дистанционных образовательных технологий. После вынужденного перехода к повсеместной дистанционной форме обучения, как мере защиты от пандемии, в локальный акт колледжа Положение об организации обучения с использованием дистанционных образовательных технологий - были внесены коррективы, касающиеся реализации модели применения ДОТ в условиях временного перевода всех 
обучающихся на обучение с применением дистанционных образовательных технологий в связи с карантинными или иными особыми обстоятельствами. Было организовано методическое сопровождение педагогических работников по переходу на онлайн-обучение, оказана информационная и организационнометодическая поддержка, постоянное онлайн-консультирование с применением всех возможных средств коммуникации. При необходимости преподавателям была предоставлена возможность взять в колледже компьютерную технику для организации онлайн-обучения студентов. Особое внимание было уделено студентам: вся необходимая для них информация об обучении была размещена на сайте колледжа, в личном кабинете студента на сайте Академии (Lk/ranepa.ru), в группах в социальных сетях, организовано постоянное консультирование студентов и их родителей (законных представителей), организовано психолого-педагогическое сопровождение, а также переведены в дистанционный формат многочисленные воспитательные мероприятия досугового, интеллектуально-познавательного и развлекательного характера. Для студентов преподавателями учебных дисциплин, МДК, руководителями учебных практик были разработаны индивидуальные графики обучения, в которых указаны даты, конкретный объем учебного материала со ссылками на электронные учебные курсы, ресурсы электронных библиотечных фондов, способы коммуникации с преподавателем.

Цифровая трансформация основ образовательного процесса требует решения проблем мотивации педагогов к активному использованию инновационных технологий; руководство колледжа постоянно совершенствует систему мотивации педагогов, причем как материальный, так и нематериальный аспекты. Разработка и использование электронных образовательных ресурсов учитываются в рейтинговой системе оценки деятельности преподавателей; победители и призеры конкурсов на лучший ЭОР обязательно поощряются; достижения педагогов отмечаются на заседаниях педагогических советов, предметно-цикловых комиссий, совещаниях.

В колледже постоянно совершенствуются условия работы преподавателей, в том числе способствующие развитию цифровой образовательной среды. Педагоги колледжа активно предлагают новые идеи, делятся с коллегами своим опытом в данной сфере. В конце 2019/2020 учебного года перед коллективом КМПО стояла непростая задача завершения учебного года, организации и проведения не только промежуточной, но и 
государственной итоговой аттестации выпускников с применением дистанционных образовательных технологий. Для решения данной задачи была проведена большая подготовительная работа, организационно-методическая работа с педагогическими работниками, организационно-педагогическое и психологическое сопровождение студентов. В итоге коллектив успешно справился с поставленными задачами, которые были новыми для колледжа и решались впервые.

Полученный опыт решения различного рода задач в рамках применения дистанционных образовательных технологий в массовом формате выявил ряд проблемных моментов, для преодоления которых будут внесены определенные коррективы в программу колледжа «Цифровая образовательная среда».

Система запланированных мероприятий позволит КМПО привести образовательные программы в соответствие с нуждами цифровой экономики, широко внедрить цифровые инструменты учебной деятельности и целостно включить их в информационную среду, обеспечить возможность обучения студентов по индивидуальному учебному плану в течение всего срока освоения профессиональных образовательных программ СПО по специальностям, в любое время и в любом месте.

\section{Список литературы}

1. Аккредитация в образовании: информационно-аналитический журнал. - 2019. - № 6 (114).

2. Информационный сервис для профессионального образовательного сообщества «Агрегатор новостей образования». - URL: https://akvobr.ru/ cifrovaya_obrazovatelnaya_sreda_ehto. html (дата обращения: 21.05.2021).

3. Кузнецов Н.В. Онлайн-образование: ключевые тренды и перспективы/Н.В. Кузнецов// E-Management. - 2019. - Т2, №1. - С.19-25.

4. Об утверждении Целевой модели цифровой образовательной среды: [приказ Министерства просвещения РФ от 02.12.2019 № 649, зарегистрирован в Минюсте РФ 24.12.2019, регистрационный № 56962] // Правовая база Гарант. 2021. - URL: https://www.garant.ru/(дата обращения: 03.06.2021).

5. Петрова, Н.П. Цифровизация и цифровые технологии в образовании / Н. П. Петрова,Г. А. Бондарева // Мир науки, культуры, образования. - 2019. - № 5 (78). - C. 353-355. 
6. Сташкевич, И.Р. Информатизация как стратегический фактор развития профессионального образования / И. Р. Сташкевич // Инновационное развитие профессионального образования. - 2016. — № 4 (12). - С. 25-28. 